\title{
Analysis of Predictive Thermodynamic Models for Estimation of Polycyclic Aromatic Solid Solubility in Hot Pressurized Water
}

\author{
Tiziana Fornari ${ }^{1, *}$, Elena Ibañez ${ }^{1}$, Guillermo Reglero ${ }^{1}$ and Roumiana P. Stateva ${ }^{2}$ \\ ${ }^{I}$ Instituto de Investigación en Ciencias de la Alimentación CIAL (CSIC-UAM) C/Nicolás Cabrera 9, Universidad \\ Autónoma de Madrid, 28049 Madrid, Spain \\ ${ }^{2}$ Institute of Chemical Engineering, Bulgarian Academy of Sciences, Sofia 1113, Bulgaria
}

\begin{abstract}
The ability of two thermodynamic approaches to predict the solubility of solid compounds in hot pressurized water is studied and compared. The Regular Solution Theory, based on the solubility parameter concept, and UNIFACbased models were applied to calculate the solute activity coefficient and then, solubility predictions were compared with experimental data reported in the literature. The analysis was carried out considering polycyclic aromatic hydrocarbons as model substances, i.e. substances which contain only the aromatic $\mathrm{AC}$ and $\mathrm{ACH}$ groups, and for which reliable pure physical properties such as melting point, fusion enthalpy and molar volume are available in the literature. The solubility values predicted with the UNIFAC-based models were considerably better than those obtained with the solubility parameter approach. Particularly, the modified Dortmund UNIFAC model presented an appropriate functionality of solubility with temperature, and the extension of this model to other type of aromatic compounds also provided a satisfactory prediction of solubility data.
\end{abstract}

Keywords: Aromatic hydrocarbons, Regular Solution Theory, Solid solubility, Suberitical water, Thermodynamic modeling, UNIFAC.

\section{INTRODUCTION}

Hot pressurized water (HPW), also called subcritical water, is gaining increasing applications as a green extraction solvent. Depending on temperature, it can be very effective to selectively extract a variety of polar or non-polar organic compounds from many different matrices. Some practical applications involve the extraction of alkyl benzenes from industrial soil and petroleum waste sludge [1], polychlorinated biphenyls from soil and river sediments [2], therapeutic substances from different plant matrices [3-5], natural antioxidants from aromatic plants $[6,7]$, etc. Recent reviews presented numerous applications of subcritical water extraction to recover high added value substances from natural matter $[8,9]$.

The main feature concerned with the extraction of hydrophobic organic compounds using water is the decrease of water polarity (measured by its dielectric constant) with increasing temperature. Thus, raising temperature with enough pressure to maintain water in the liquid state has a dramatic effect on the solubility of non-polar compounds. Proper representation of the solute + subcritical water phase behavior is particularly important, in order to select the optimum extraction temperature.

In recent years, many efforts have been made to develop semi-empirical approaches [10-13] to correlate the solubility

\footnotetext{
*Address correspondence to this author at the Instituto de Investigación en Ciencias de la Alimentación CIAL (CSIC-UAM) C/Nicolás Cabrera 9, Universidad Autónoma de Madrid, 28049 Madrid, Spain;

Tel: +34910017927; Fax: +34910017900;

E-mail: tiziana.fornari@uam.es
}

of solids in HPW, based on the use of solute and solvent (water) physical properties. For example, Miller et al. [10] developed a simple equation to relate the effect of increasing temperature on the solubility of polycyclic aromatic hydrocarbons (PAHs) in liquid water at high temperatures. The authors used a single parameter, i.e. the solubility of the solute at ambient temperature, to estimate its solubility at higher temperatures. Del Valle et al. [12] demonstrated the strong effect of other factors, such as critical temperature and acentric factor of the pure solute, and developed a new semi-empirical relationship for the solute solubility in HPW as a function of temperature. The results obtained demonstrated an excellent correlation of the solubility of 34 different compounds including PAHs, pesticides, flavanoidtype compounds and some essential oil components in HPW.

Another semi-empirical relationship, presented by Karásek et al. [13], uses the temperature dependency of pure water physical properties (internal pressure, cohesive energy density and dielectric constant) to correlate the activity coefficients of PAHs in water as a function of temperature. Pure solute physical properties (fusion enthalpy, triple-point temperature, subcooled liquid molar and solid molar volumes) are employed to calculate the ratio of the solute fugacity in the solid and subcooled liquid states, and high degree of correlation of the experimental solubility data was achieved [13].

The above mentioned approaches [10-13] are based on the use of physical properties of both the solute and water (i.e. no energy interactions between like or unlike molecules are considered) and are good correlative methods but are not predictive tools. 
Recently, Fornari et al. [14] investigated the capabilities of UNIFAC-based models to predict the solubility of PAHs in subcritical water. The original UNIFAC [15], its modified (Dortmund) version [16] and the (associative) A-UNIFAC model [17] were applied in the temperature range (298 to $500) \mathrm{K}$. These models are based on the group contribution approach to take into account the energy interactions among molecules. Despite the fact that A-UNIFAC is specifically targeted to accounting for the association effects between molecules, the best prediction of solubility data was obtained with the modified Dortmund UNIFAC version. Hansen et al. [18] also emphasized the goodness of this UNIFAC version to predict the solubility of anthracene, fluoranthene and pyrene in polar solvents.

In this work, the predictive capabilities of the UNIFACbased models and approaches based on Regular Solution Theory (RST) [19] to represent the solubility of PHAs in subcritical water are compared. Furthermore, the group contribution procedure developed by Fedors [20] to calculate Hildebrand Solubility Parameter was compared with solubility predictions resulting from applying the Three Dimensional Hansen Solubility Parameter [21].

The Scatchard-Hildebrand theory has been effectively used as a screening tool in the case of athermal solutions (i.e. non-polar or slightly polar systems) to find out the best solvent for a given solute, usually at ambient temperature [19]. This theory is based on the presumption that dispersive interactions are the only kind of intermolecular forces in the mixture and thus, it is expected that predictions will not be satisfactory in the case of water + PAH systems. Nevertheless, it is also expected that predictions should improve with increasing temperature since water polarity decreases with temperature (i.e. the water $+\mathrm{PAH}$ mixture should better suit the regular solution concept at high temperature).

On the other side, Hansen Solubility Parameter theory appears to be more appropriate to represent solid solubility in HPW since the solubility parameter of a compound depends on the contribution of not only dispersive, but also polar and hydrogen bonding forces. This theory has been traditionally used to study the interactions of polymeric and biological compounds with a variety of solvents. Provided the interactions of a given compound with a range of chemicals are known then it is possible to plot Hansen spheres that depict the miscibility range of the compound under study [22].

\section{THERMODYNAMIC FRAMEWORK}

The fundamental equi-fugacity equilibrium condition for liquid water (1) and a pure solid solute (2) is:

$f_{2}^{S}=f_{2}^{L}$

where $f_{2}^{S}$ is the fugacity of the solute in the solid phase and $f_{2}^{L}$ is the fugacity of the solute in the liquid water phase. If the solid phase is a pure compound, then the fugacity of the pure solid solute $f_{2}^{S}$ equals its fugacity in the solvent, assuming complete immiscibility with the solvent in the solid state.
The solute fugacity in the liquid phase can be referred to the fugacity of the pure solute in liquid state $f_{2}^{o}$ :

$f_{2}^{L}=\gamma_{2} x_{2} f_{2}^{o}$

where $\gamma_{2}$ is the activity coefficient of the solute in the liquid phase, $x_{2}$ is its molar fraction (solubility) and $f_{2}^{o}$ is the liquid-phase standard state fugacity that typically is taken as the pure-liquid fugacity at the system temperature and at pure-liquid vapor pressure, with the corresponding corrections for pure-fluid vapor-phase non-ideality and for the effect of total pressure.

Replacing Eq. (2) in Eq. (1) the following relation for the solubility is obtained:

$\ln x_{2}=\ln \left(f_{2}^{S} / f_{2}^{o}\right)-\ln \gamma_{2}$

When the mixture temperature is lower than the solute triple point temperature, $f_{2}^{o}$ stands for the pure solute in a hypothetical liquid state. Additionally, for most substances, there is little difference between the triple point temperature and the normal melting temperature. Thus, the ratio $f_{2}^{S} / f_{2}^{o}$ can be calculated as follows:

$$
\begin{aligned}
& \ln \left(f_{2}^{S} / f_{2}^{o}\right)=-\frac{\Delta H_{m 2}}{R T_{m 2}}\left(\frac{T_{m 2}}{T}-1\right) \\
& +\frac{\Delta C_{p 2}}{R}\left[\left(\frac{T_{m 2}}{T}-1\right)+\ln \left(\frac{T}{T_{m 2}}\right)\right]-\int_{P_{s o t}}^{P} \frac{V_{2}^{L i q}-V_{2}^{S}}{R T} d P
\end{aligned}
$$

where $T_{\mathrm{m}_{2}}$ and $\Delta H_{\mathrm{m}_{2}}$ are, respectively, the solute normal melting temperature and enthalpy of fusion, and $\Delta C_{p 2}$ is the difference between the heat capacity of the pure liquid and solid solute. The first term on the right-hand side of Eq. (4) is the dominant; the second term is often considered as being small, as the opposite signs of the enthalpic and entropic correction lead to near cancellation, especially if the mixture temperature and the solute melting temperature are not far apart. Finally, the last term of Eq. (4), which takes into account the effect of pressure on the solute fugacity, is significant only at very high pressures since the difference between the solute molar volume in the liquid and solid states is negligible.

Introducing the above standard simplifications in Eq. (4):

$$
\ln \left(f_{2}^{S} / f_{2}^{o}\right)=-\frac{\Delta H_{m 2}}{R T_{m 2}}\left(\frac{T_{m 2}}{T}-1\right)
$$

and provided the solute-water mixture is assumed to be ideal $\left(\gamma_{2}=1\right)$, allows obtaining the following expression for the ideal solubility:

$\ln x_{2}^{i d}=-\frac{\Delta H_{m 2}}{R T_{m 2}}\left(\frac{T_{m 2}}{T}-1\right)$

Thus, according to Eq. (6), the ideal solute solubility depends only on its melting properties and on the system temperature.

Fig. (1) shows a comparison between the experimental solubility of several PAHs at $T^{0}=298 \mathrm{~K}$, with the ideal 


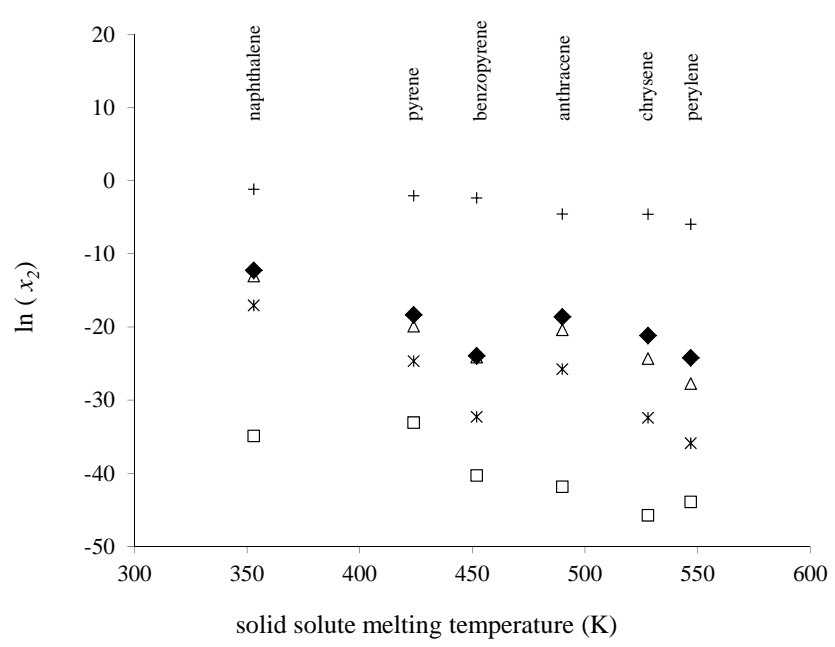

Fig. (1). Solubility of PAHs in subcritical water at $298 \mathrm{~K}$ : (•) experimental data $[8,10,11]$; (+) ideal solubility (Eq. 6); ( $\square$ ) RSTFedors; (*) RST-Hansen; $(\triangle)$ original UNIFAC model.

solubility predicted by Eq. (6). The melting properties of the pure solutes were obtained from the literature and are given in Table 1, together with the references for the source of the experimental data. As expected, there are considerable differences between the experimental solubility and the values calculated according to Eq. (6), since water $+\mathrm{PAH}$ mixtures are strongly non-ideal solutions.

Taking into account Eq. (6), Eq. (3) can be re-written as follows: $\ln x_{2}=\ln x_{2}^{i d}-\ln \gamma_{2}$

In this work, the solute activity coefficient in the liquid phase, which quantifies the deviation from the ideal contribution term, is calculated using (i) the RST-based models and (ii) UNIFAC-based group contribution methods.

\section{RESULTS AND DISCUSSION}

According to the Schatchard-Hildebrand RST, the solubility $\left(x_{2}\right)$ of a solid solute in a liquid is given by [19]:

$$
\ln \gamma_{2}=\frac{V_{2}}{R T} \varphi_{1}^{2}\left(\delta_{1}-\delta_{2}\right)^{2}
$$

where $V_{2}$ is the solute molar volume in a hypothetical liquid state (usually the melting temperature of the solid solute is higher than the mixture temperature), $V_{l}$ is the molar volume of the liquid solvent (water), $\varphi_{1}=\left(x_{1} V_{1}\right) /\left(x_{1} V_{1}+x_{2} V_{2}\right)$ is the volume fraction of water, and $\delta_{1}$ and $\delta_{2}$ are, respectively, the water and solute solubility parameter, defined by:

$\delta_{i}=\left[\frac{\Delta U_{i}}{V_{i}}\right]^{1 / 2} \quad i=1,2$

where $\Delta U_{i}$ is the vaporization energy and $V_{i}$ is the liquid molar volume.

Fig. (1) shows a comparison between the experimental solubility of different PHAs at $T^{0}=298 \mathrm{~K}$ and the values calculated using Eqs. (6-8). The value for the water solubility parameter $\delta_{1}^{0}=47.9(\mathrm{MPa})^{1 / 2}$ was calculated from Eq. (9)

Table 1. Melting Properties of the Solid Solute Compounds Considered in this Work

\begin{tabular}{|c|c|c|c|c|}
\hline & Molecular Weight & $T_{\mathrm{m}_{2}}{ }^{\mathrm{a}}(\mathbf{K})$ & $\Delta H_{\mathrm{m}_{2}}\left(\mathrm{~J} \cdot \mathrm{mol}^{-1}\right)$ & Ref. for Exp. Solubility Data \\
\hline Naphthalene & 128.17 & 353 & $19000^{\mathrm{a}}$ & [11] \\
\hline Anthracene & 178.23 & 490 & $29000^{\mathrm{a}}$ & {$[10]$} \\
\hline Perylene & 252.31 & 547 & $32580^{\mathrm{a}}$ & {$[10]$} \\
\hline Benzo-pyrene & 252.31 & 454 & $17320^{\mathrm{a}}$ & [11] \\
\hline Pyrene & 202.25 & 424 & $17360^{\mathrm{a}}$ & {$[10]$} \\
\hline Chrysene & 228.29 & 528 & $26150^{\mathrm{a}}$ & {$[10]$} \\
\hline Carbazole & 167.21 & 515 & $27200^{\mathrm{a}}$ & {$[10]$} \\
\hline Alizarin & 240.21 & $562-566$ & $29272^{\mathrm{b}}$ & {$[8]$} \\
\hline Chlorothalonil & 265.91 & $523-524$ & $22882^{b}$ & {$[11]$} \\
\hline Propazine & 229.71 & $485-489$ & $24714^{\mathrm{b}}$ & {$[11]$} \\
\hline Atrazine & 215.68 & $446-450$ & $21433^{\mathrm{b}}$ & {$[8]$} \\
\hline Simazine & 201.70 & $498-500$ & $35415^{\mathrm{b}}$ & {$[8]$} \\
\hline
\end{tabular}

${ }^{a}$ http://webbook.nist.gov/chemistry/ [23]

${ }^{\mathrm{b}}$ Estimated in this work applying the method of Jain et al. [24]. 
using experimental enthalpy $\left(\Delta H_{1}^{0}=41.4 \mathrm{~kJ} \cdot \mathrm{mol}^{-1}\right)$ and molar liquid volume data $\left(V_{1}^{0}=18.1 \mathrm{~cm}^{3} \cdot \mathrm{mol}^{-1}\right)$. The solubility parameter and the hypothetical liquid volume of each of the solutes were estimated following the group contribution method proposed by Fedors [20] and are given in Table 2. Fig. (1) also displays the solubility values obtained when $\gamma_{2}$ in Eq. (7) is calculated using the original UNIFAC group contribution approach.

Table 2. Solubility Parameter and Liquid Volume of Polycyclic Aromatic Hydrocarbons Estimated Using Fedors' Group Contribution Approach $\left(T^{0}=298 \mathrm{~K}\right)$

\begin{tabular}{|l|c|c|}
\hline & $\left.\delta_{\mathbf{2}}^{\mathbf{0}} \mathbf{( M P a}\right)^{\mathbf{1 / 2}}$ & $V_{\mathbf{2}}^{\mathbf{0}} \mathbf{c m}^{\mathbf{3}} / \mathbf{m o l}$ \\
\hline \hline Naphthalene & 21.3 & 118.0 \\
\hline Anthracene & 22.7 & 145.6 \\
\hline Perylene & 24.8 & 176.0 \\
\hline Benzo-pyrene & 24.8 & 176.0 \\
\hline Pyrene & 25.2 & 148.4 \\
\hline Chrysene & 23.6 & 173.2 \\
\hline
\end{tabular}

According to the results shown on Fig. (1), the original UNIFAC model can provide, at $T^{0}=298 \mathrm{~K}$, a much better and a completely acceptable estimation of the solubility of PHAs in water in comparison with the RST-Fedors model. Nevertheless, one possible source for the considerable differences between the experimental and calculated solubility values obtained with the RST could be the use of non-adequate values for $V_{2}^{0}$ and $\delta_{2}^{0}$ which were estimated applying the group contribution approach of Fedors [20]. Thus, particular attention was paid to the accuracy with which this method predicts PHAs solubility parameters and liquid molar volumes. In order to analyze that, Eq. (9) was employed to calculate the solubility parameter of two PHAs, namely naphthalene and anthracene, for which the required physical properties are known (Table 3). In Eq. (9) the term $\Delta U_{i}$ is also known as the cohesive energy term and is equal to $\Delta H^{v a p}-R T$. The enthalpy of vaporization was estimated as the difference between the sublimation and fusion enthalpies (see Table 3). An accurate value of, respectively, naphthalene and anthracene molar volume in the (hypothetical) liquid state at $298 \mathrm{~K}$ was calculated by correlating experimental liquid molar volumes (see Fig. 2). An expansion coefficient $\alpha_{2}=0.011 \mathrm{~K}^{-1}$ was obtained for both PHAs, and extrapolation of the linear correlation to 298 $\mathrm{K}$ provided values for naphthalene and anthracene liquid volume $\left(V_{2}^{0}\right)$ of, respectively, $122.4 \mathrm{~cm}^{3} \cdot \mathrm{mol}^{-1}$ and 151.2 $\mathrm{cm}^{3} \cdot \mathrm{mol}^{-1}$. These values are in good agreement with the values given in Table 2, being in both cases around $4 \%$ higher than those predicted using Fedors' method.

Taking into account Eq. (9) the solubility parameter of naphthalene and anthracene were calculated (Table 3). The results obtained are also in an excellent agreement with Fedors' approach (Table 2). Finally, the $V_{2}^{0}$ and $\delta_{2}^{0}$ parameters of Table $\mathbf{3}$ were applied to calculate naphthalene and anthracene solubility in water at $298 \mathrm{~K}$. As can be observed, the solubility predictions are quite similar (and not better) than those obtained using RST-Fedors approach (see Table 3). Thus, it can be concluded with a high degree of certainty that the deficiency of the RST approach (Fig. 1) cannot be attributed to the use of Fedors' method to estimate the PAHs parameters.

In order to investigate the capability of the RST approach to predict the variation of $\mathrm{PAH}$ solubility with temperature, the following procedure was adopted.

Table 3. Physical Properties of Naphthalene and Anthracene Employed in the Calculation their Solubility Parameter by Means of Eq. (9)

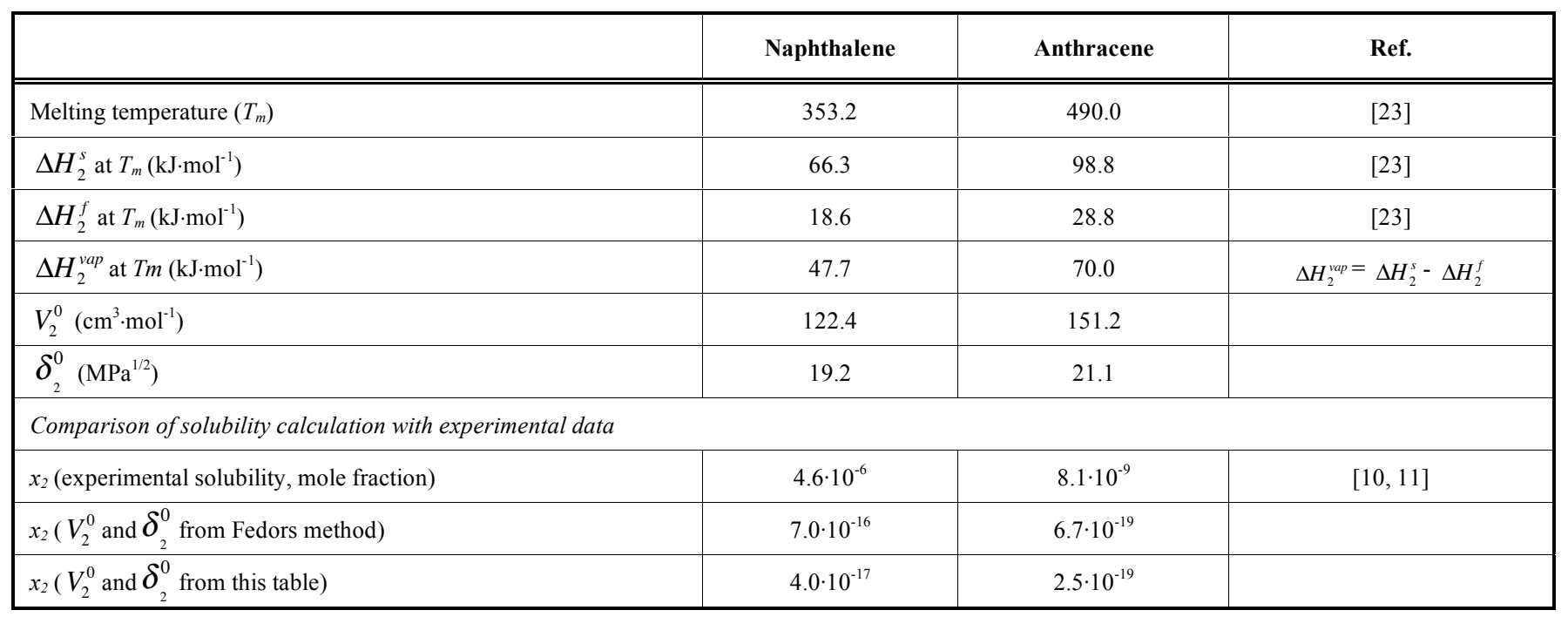




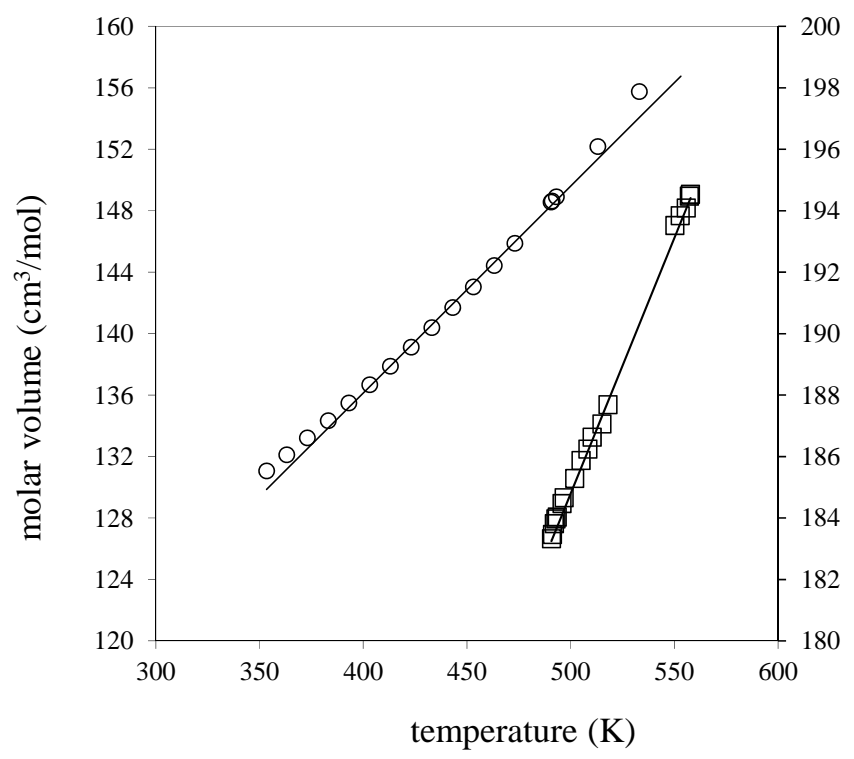

Fig. (2). Experimental $(\bigcirc)$ naphthalene [25] and ( $\square$ ) anthracene [26] liquid molar volume as a function of temperature. Solid line: lineal correlation given by Eq. (10).

On one hand, the temperature dependence deduced for naphthalene and anthracene liquid molar volume, i.e.:

$V_{2}=V_{2}^{0}\left[1+\alpha\left(T-T^{0}\right)\right]$

was applied to establish the temperature dependence for the PAHs solubility parameter as proposed by Fedors [20]:

$\delta_{2}=\delta_{2}^{0}\left(V_{2}^{0} / V_{2}\right)^{1.13}$

where $\delta_{2}^{0}$ is Fedors' solubility parameter at $298 \mathrm{~K}$. For the sake of comparison, Eqs. (10) and (11) were applied to calculate anthracene solubility parameter at its triple point, which resulted to be $18.2 \mathrm{MPa}^{1 / 2}$. Again, this prediction is in a very good agreement with the experimental value of 18.9 $\mathrm{MPa}^{1 / 2}$ reported by the DIPPR database [27].

On the other hand, the variation of water solubility parameter $\left(\delta_{1}\right)$ with temperature was considered by applying Eq. (9) and using water steam tables to calculate $\Delta U_{1}$ and $V_{1}$ as a function of temperature.

Considering the temperature dependence of $\delta_{1}$ and $\delta_{2}$ as explained above, the solubility of naphthalene and anthracene were calculated using the RST-Fedors model and were compared with the experimental data (see Fig. 3). As expected, the RST-Fedors predictions greatly improve with increasing temperature since water becomes less polar and the $\mathrm{PAH}+$ water mixture becomes more similar to a regular solution.

Fig. (3) also shows a comparison between the experimental PAHs solubility in water and the values predicted using the original and modified (Dortmund) UNIFAC models to estimate the activity coefficient. Definitely, the UNIFAC-based models provide better predictions than those obtained with the RST-Fedors model, although the deviations between experimental values and UNIFAC predictions increase with temperature. This effect should be attributed to the fact that the UNIFAC energy interaction parameters have been obtained correlating experimental phase equilibrium data which normally contains few high molecular weight compounds and high temperature data points.

Table 4 shows the average absolute deviations $(A A D \%)$ :

$$
A A D \%=\frac{100}{N_{\exp }} \sum_{i=1}^{N_{\exp }}\left|\frac{\ln x_{2}^{\exp }-\ln x_{2}^{c a l}}{\ln x_{2}^{\exp }}\right|
$$
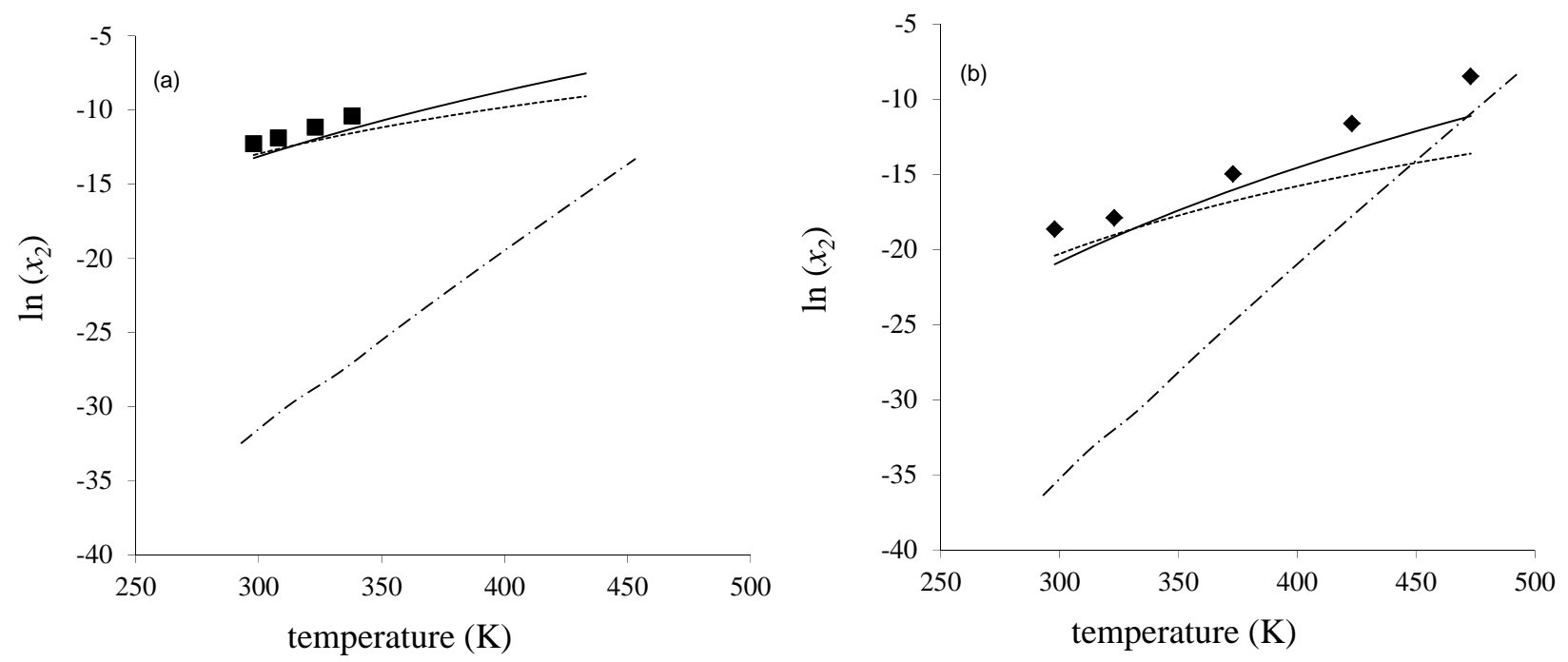

Fig. (3). Solubility of (a) naphthalene and (b) anthracene in subcritical water as a function of temperature: $(-\cdot-\cdot-)$ RST-Fedors method; (- - - -) original UNIFAC; (- $(-)$ modified UNIFAC. 
Table 4. Absolute Average Deviation (AAD\%) Obtained with the Original and Modified UNIFAC Models and with the RSTFedors Approach in the Prediction of PAH Solubility in Subcritical Water in the Temperature Range (298 to 493$) \mathrm{K}$

\begin{tabular}{|l|c|c|c|}
\hline System: Water + & Original UNIFAC & Modified UNIFAC & RST-Fedors Model \\
\hline \hline Naphthalene & 7.9 & 7.6 & 68.3 \\
\hline Anthracene & 23.6 & 14.7 & 33.5 \\
\hline Perylene & 29.2 & 21.8 & 30.2 \\
\hline Benzo-pyrene & 43.4 & 20.9 & 58.2 \\
\hline Pyrene & 13.9 & 12.9 & 43.7 \\
\hline Chrysene & 34.2 & 22.2 & 61.9 \\
\hline Total $A A D \%$ & 26.5 & 17.3 & \\
\hline
\end{tabular}

obtained applying the RST-Fedors approach and both the original and modified UNIFAC models. For all PAH + water systems studied, the predictions obtained with the UNIFACbased models are significantly better than the results obtained with the RST-Fedors approach. Further, the $A A D \%$ values obtained with the modified UNIFAC model are considerably lower than those obtained with its original version (see Table 4 and Fig. 3).

An extended Hansen method, incorporating Hansen solubility parameters into a modified Schatchard-Hildebrand equation to calculate the solute activity coefficient [28], was also applied to predict the solubility of PHAs in water in order to ascertain the capability of the RST-based models. The solute activity coefficient is given by:

$$
\begin{aligned}
& \ln \gamma_{2}=\frac{V_{2}}{R T}\left[\left(\delta_{d, 2}-\delta_{d, 1}\right)^{2}+0.25\left(\delta_{p, 2}-\delta_{p, 1}\right)^{2}+0.25\left(\delta_{h, 2}-\delta_{h, 1}\right)^{2}\right] \\
& +1-\frac{V_{2}}{V_{1}}+\ln \left(\frac{V_{2}}{V_{1}}\right)
\end{aligned}
$$

where $\delta_{d}, \delta_{p}$, and $\delta_{h}$ are the dispersion, polar, and hydrogenbonding Hansen solubility parameters, respectively.

To estimate the dispersion, polar and hydrogen-bonding contribution to the PAHs solubility parameters, the group contribution approach of Stefanis and Panayiotou [29] was employed, while the water contributions $\left(\delta_{d, l}=15.5, \delta_{p, 1}=\right.$ 16.0 and $\delta_{h, l}=42.3$ ) were taken from the literature [30]. Table 5 shows the corresponding contributions and the total Hansen solubility parameter $\left(\delta_{\text {HANSEN }}=\sqrt{\delta_{d}^{2}+\delta_{p}^{2}+\delta_{h}^{2}}\right)$ obtained. The table also displays a comparison of $\delta_{H A N S E N}$ with the solubility parameters calculated using Fedors' group contribution approach. The predicted PAHs' solubility in water at $298 \mathrm{~K}$ are depicted in Fig. (1) and compared with the rest of the results obtained in this work. As can be observed, the solubilities predicted by the RST-Hansen approach are significantly better than those predicted using RST-Fedors approach. The average absolute deviations obtained were, respectively, $109.1 \%$ for RST-Fedors method and $41.3 \%$ in the case of RST-Hansen approach. Furthermore, it should be pointed out that when the Hansen solubility parameters (Table 5) were used to calculate the PAHs activity coefficients (Eq. 8), predictions are similar $(A A D=104.4 \%)$ to those obtained with the RST-Fedors method. That is, the considerably improved predictions achieved with the RST-Hansen method is a consequence of the application of the modified Schatchard-Hildebrand equation (Eq. 13).

Despite the improvement obtained with the RST-Hansen approach, calculations with UNIFAC-based models always

Table 5. Comparison Between the Values of the Solubility Parameters Employed in the RST-Fedors and RST-Hansen Approaches

\begin{tabular}{|c|c|c|c|c|c|}
\hline & $\delta_{d}$ & $\delta_{p}$ & $\delta_{h}$ & $\delta_{\text {HANSEN }}{ }^{a}$ & $\delta_{\text {FEDORS }}$ \\
\hline Naphthalene & 19.90 & 4.35 & 4.55 & 20.87 & 21.3 \\
\hline Perylene & 25.41 & 5.94 & 2.88 & 26.25 & 24.8 \\
\hline Benzo-pyrene & 25.41 & 5.94 & 2.88 & 26.25 & 24.8 \\
\hline Chrysene & 23.72 & 4.70 & 2.86 & 24.35 & 23.6 \\
\hline
\end{tabular}
to Predict PAHs Solubility in Water at $298 \mathrm{~K}$

${ }^{a} \delta_{\text {HANSEN }}=\sqrt{\delta_{d}^{2}+\delta_{p}^{2}+\delta_{h}^{2}}$ 
resulted in much better predictions. For the sake of illustration, the $A A D$ in the solubility predictions applying the modified UNIFAC model (Fig. 1) is $10.1 \%$.

Modified UNIFAC was also applied in even wider predictive mode to estimate the solubility of other solid compounds, e.g. carbazole, chlorothalonil and alizarin, which comprise additional functional groups to the $\mathrm{AC}$ and $\mathrm{ACH}$ aromatic groups. Values for the enthalpy of fusion of these compounds were not available in the literature and were estimated in this work applying the method of Jain et al. [24] (see Table 1). The $A A D$ obtained in the prediction were $(24.1,21.0$ and 7.5$) \%$, respectively, for carbazole, chlorothalonil and alizarin, considering a total of 15 data points and covering a temperature range from (298 to 493) $\mathrm{K}$.

Due to the lack of adequate groups in the modified UNIFAC table to represent the chemical structure of pesticides (propazine, atrazine and simazine) a new chlorotriazine $(\mathrm{CN})_{3} \mathrm{Cl}$ group was defined (see Fig. 4). Its volume and area parameters were calculated following Bondi [31] and the values obtained were $R_{w}=2.7429$ and $Q_{w}=1.4200$. The melting temperatures for these pesticide compounds were obtained from the literature [23] and the corresponding fusion enthalpies were estimated according to the method of Jain et al. [24]. By fitting binary interaction parameters between the $n(\mathrm{CN})_{3} \mathrm{Cl}$ group and $m \mathrm{H}_{2} \mathrm{O}\left(a_{n m}=970 \mathrm{~K}, a_{m n}=\right.$ $160 \mathrm{~K}, b_{n m}=-1.24, b_{m n}=0.0$ and $c_{n m}=-0.003 K^{-1}, c_{m n}=0.0$ ) a satisfactory correlation of the pesticides solubility in water was achieved (see Fig. 5) with an $A A D$ of $5.3 \%$.<smiles>Clc1ncncn1</smiles>

Fig. (4). Chloro-triazine $(\mathrm{CN})_{3} \mathrm{Cl}$ group chemical structure.

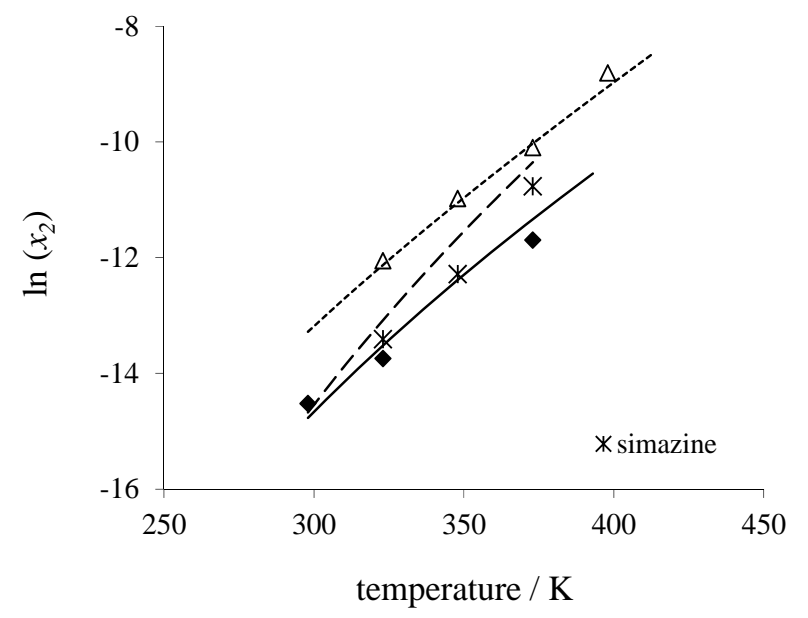

Fig. (5). Comparison between experimental solubility of several pesticides, $(\bullet)$ propazine, $(\Delta)$ atrazine and $(*)$ simazine, in solubility in HPW and values calculated using the modified UNIFAC model. References for experimental solubility data are given in Table $\mathbf{1}$.

\section{CONCLUSIONS}

This work explores the capabilities of several wellknown thermodynamic models to predict the solubility of polycyclic aromatic hydrocarbons in hot pressurized water. As expected, the high nonideality of the PAH + water mixture - not only due to water polarity but also because of their size-asymmetry - resulted in poor predictive capability of models based on the Regular Solution Theory. That is, both presumptions embedded in the RST concept, i.e. dispersive interactions as the only kind of intermolecular interactions the zero excess volume, resulted in poor predictions. On the other hand the modified (Dortmund) UNIFAC model, which comprises a combinatorial contribution suitable for compounds very different in size and a set of temperature-dependent dispersive interaction parameters, provided satisfactory predictions, in a wide range of temperatures, by applying the extensive and wellknown liquid-vapor parameter table.

\section{CONFLICT OF INTEREST}

None Declared

\section{ACKNOWLEDGEMENT}

This work has been financed by project S2009-AGR1469 from the Comunidad Autónoma de Madrid (Spain) and CSD2007-00063 FUN-CFOOD (Programa CONSOLIDERINGENIO 2010) project.

\section{REFERENCES}

[1] Y. Yang, S. B. Hawthorne, and D. J. Miller, "Class-selective extraction of polar, moderately polar, and nonpolar organics from hydrocarbon wastes using subcritical water", Environ. Sci. Technol., vol. 31, pp. 430-437, 1997.

[2] K. Hartonen, K. Inkala, M. Kangas, and M. L. Riekkula, "Extraction of polychlorinated biphenyls with water under subcritical conditions", J. Chromatogr., vol. 785, pp. 219-226, 1997.

[3] A. Shotripuk, J. Kiatsongserm, P. Pavasant, M. Goto, and M. Sasaki, "Pressurized hot water extraction of anthraquinones from the roots of morinda citrifolia", Biotechnol. Prog., vol. 20, pp. 1872-1875, 2004.

[4] M. H. Eikania, F. Golmohammada, and S. Rowshanzamirb, "Subcritical water extraction of essential oils from coriander seeds (Coriandrum sativum L.)", J. Food Eng., vol. 80, pp. 735-740, 2007.

[5] M. García-Marino, J. C. Rivas-Gonzalo, E. Ibáñez, and C. GarcíaMoreno, "Recovery of catechins and proanthocyanidins from winery by-products using subcritical water extraction", Anal. Chim. Acta., vol. 563, pp. 44-50, 2006.

[6] E. Ibañez., A. Kubatova, F. J. Senorans, S. Cavero, G. Reglero, and S. B. Hawthorne, "Subcritical water extraction of antioxidant compounds from rosemary plants", J. Agric. Food Chem., vol. 51, pp. 375-382, 2003.

[7] I. Rodríguez-Meizoso, F. R. Marin, M. Herrero, F. J. Señorans, G. Reglero, A. Cifuentes, and E. Ibáñez, "Subcritical water extraction of nutraceuticals with antioxidant activity from oregano. Chemical and functional characterization", J. Pharm. Biomed. Anal., vol. 41, pp. 1560-1565, 2006.

[8] W. King, "Pressurized water extraction: resources and techniques for optimizing analytical applications", In: Modern extraction techniques: food agricultural sample. C. Turner, Ed. Washington, DC: American Chemical Society, pp. 79-95, 2006.

[9] Ch. Turner, E. Ibañez, "Pressurized hot water extraction", In: Lebovka, Vorobiev \& Chemat, Eds. Enhancing Extraction Processes in the Food Industry, Taylor \& Francis Group, LLC (in press). 
[10] D. J. Miller, S. B. Hawthorne, A. M. Gizir, and A. A. Clifford, "Solubility of polycyclic hydrocarbons in subcritical water from 298 K to 498 K", J. Chem. Eng. Data, vol. 43, pp. 1043-1047, 1998.

[11] D. J. Miller, and S. B. Hawthorne, "Method for determining the solubility of hydrophobic organics in subcritical water", Anal. Chem., vol. 70, pp. 1618-1621, 1998.

[12] J. M. del Valle, J. C. de la Fuente, and J. W. King, "Correlation for the variation with temperature of solute solubilities in hot pressurized water", Proceedings of the VII Iberoamerican Conference on Phase Equilibria and Fluid Properties for Process Design (Equifase 2006) Morelia, Michoacan, Mexico, October 2125 pp. 142, 2006.

[13] P. Karásek, J. Planeta, and M. Roth, "Solubility of solid polycyclic aromatic hydrocarbons in pressurized hot water: correlation with pure component properties", Ind. Eng. Chem. Res., vol. 45, pp. 4454-4460, 2006.

[14] T. Fornari, R. P. Stateva, F. J. Señorans, G. Reglero, and E. Ibañez, "Applying UNIFAC-based models to predict the solubility of solids in subcritical water", J. Supercritical Fluids, vol. 46, pp. 245-251, 2008.

[15] A. Fredenslund, R. L. Jones, and J. M. Prausnitz, "Groupcontribution estimation of activity coefficients in nonideal liquid mixtures", AIChE J., vol. 21, pp. 1086-1099, 1975.

[16] J. Gmehling, J. Li, and M. Schiller, "A modified UNIFAC model. 2. present parameter matrix and results for different thermodynamic properties", Ind. Eng. Chem. Res., vol. 32, pp. 178-193, 1993.

[17] A. C. Mengarelli, E. A. Brignole, and S. B. Bottini, "Activity coefficients of associating mixtures by group contribution", Fluid Phase Equilibria, vol. 163, pp. 195-207, 1999.

[18] H. K. Hansen, C. Riverol, and W. E. Acree Jr. "Solubilities of anthracene, fluoranthene and pyrene in organic solvents: comparison of calculated values using UNIFAC and modified UNIFAC (Dortmund) models with experimental data and values using the Mobile Order Theory", Can. J. Chem. Eng., vol. 78, 1168-1174, 2000.

[19] J. M. Prausnitz, R. N. Lichtenthaler, and E. G. Azevedo, Molecular Thermodynamics of Fluid-Phase Equilibria. Prentice Hall, Englewood Cliffs, N.J., 671-749, 1999.
[20] R. F. Fedors, "A method for estimating both the solubility parameters and molar volumes of liquids", Polymer Eng. Sci., vol. 14, pp. 147-154, 1974

[21] C. M. Hansen, "The Universality of the Solubility Parameter", Industrial and Engineering Chemistry Product Research and Development, vol. 8, pp. 2-11, 1969.

[22] Srinivas, J. W. King, J. K. Monrad, L. R. Howard, and C. M. Hansen, "Optimization of subcritical fluid extraction of bioactive compounds using hansen solubility parameters", Food Eng. Phys. Prop., vol. 74, pp. 342-354, 2009.

[23] P. Linstrom, W. Mallard, NIST Chemistry WebBook, NIST Standard Reference Database Number 69; National Institute of Standards and Technology: Gaithersburg, MD, 2005; p 20899. http://webbook.nist.gov (accessed Nov. 2007).

[24] J. G. Yang, and S. H. Yalkowsky, "Estimation of melting points of organic compounds", Ind. Eng. Chem. Res., vol. 43, pp. 7618-7621, 2004

[25] "Naphthalene"; API Monograph Series, Publication 707; American Petroleum Institute, Washington, D. C., 1978.

[26] K. Shinsaka, N. Gee, and G. R. Freeman, "Densities against temperature of 17 organic liquids and of solid 2,2dimethylpropane", J. Chem. Thermo., vol. 17, pp. 1111, 1985.

[27] R. L. Rowley, W. V. Wilding, J. L. Oscarson, Y. Yang, and N. A. Zundel, DIPPR Data compilation of pure chemical properties. Design institute for physical properties. http://dippr.byu.edu. Brigham Young University, Provo, 582, Utah, 2006.

[28] F. Ashton, C. McDermott, and A. Brench, "Chemistry of extraction of nonreacting solutes", Chapter 1. In: Handbook of Solvent Extraction, T. C. Lo, M. H. I. Baird, and C. Hanson, Eds.; Wiley: New York, 1983.

[29] E. Stefanis, and C. Panayiotou, "Prediction of hansen solubility parameters with a new group-contribution method", Int. J. Thermophys., vol. 29, pp. 568-585, 2008.

[30] C. M. Hansen. Hansen Solubility Parameters: A user's handbook, second edition. CRC Press 2007.

[31] A. Bondi, "Van der waals volumes and radii", J. Phys. Chem., vol. 3, pp. 441-451, 1964.

(C) Fornari et al.; Licensee Bentham Open.

This is an open access article licensed under the terms of the Creative Commons Attribution Non-Commercial License (http://creativecommons.org/licenses/by-nc/3.0/) which permits unrestricted, non-commercial use, distribution and reproduction in any medium, provided the work is properly cited. 